\title{
Evaluation of reliability and validity of the European Organization for Research and Treatment of Cancer Quality of Life Questionnaire (EORTC QLQ-C30,Albanian version) among breast cancer patients from Kosovo
}

This article was published in the following Dove Press journal:

Patient Preference and Adherence

19 March 2015

Number of times this article has been viewed

\author{
Selvete Shuleta-Qehaja' \\ Zoran Sterjev ${ }^{2}$ \\ Ljubica Shuturkova ${ }^{2}$ \\ 'Kosovo Medicines Agency, Rrethi \\ i spitalit (QKUK), Pristina, Kosovo; \\ 'University 'Ss Cyril and Methodius', \\ Faculty of Pharmacy, Skopje, \\ Macedonia
}

\begin{abstract}
Patients and methods: A sample of breast cancer patients ( $\mathrm{n}=62$ women) were interviewed for the European Organization for Research and Treatment of Cancer Quality of Life Questionnaire (EORTC QLQ-C30) in Albanian. Reliability of the questionnaire was considered acceptable if Cronbach's alpha was $\geq 0.70$. Item convergent-discriminant validity was tested through multitrait scaling analysis. Construct validity was tested under the hypotheses that QLQ-C30 interscale correlations would have an acceptable value of $\geq 0.40$ and as well as by known group comparisons assessing differences of patient subgroups with reference to disease stage and education level.

Results: The mean age of the patients was 50 years (standard deviation: 10.9 years). Cronbach's alpha ranged from 0.54 for the cognitive functioning scale to 0.96 for the global health quality of life $(\mathrm{GH} / \mathrm{QoL})$ scale. In multitrait scaling analysis, the strength of Spearman's correlations between an item and its own subscale was $\geq 0.40$, with the exception of item $5(\rho=0.22)$; results for item discriminant validity were satisfactory, with the exception of item 5 , which showed higher correlation with other subscales than with its own physical functioning. The Spearman's interscale coefficients generally were correlated with each other. Results of known group comparisons did not show significant differences in terms of disease stage. Regarding education level, patients with high school/university education had better functional scales scores only in certain subscales compared to other subgroups; furthermore, patients with secondary school education had better GH/QoL compared to other subgroups of patients.
\end{abstract}

Conclusion: The EORTC QLQ-C30 (v3.0) in Albanian was found to be valid and reliable for women with breast cancer and could be considered as a starting point for further evaluation study.

Keyword: women, oncology, internal consistency, functional scale, symptom scale, HRQoL

\section{Introduction}

Breast cancer is the second most common cancer in the world and, by far, the most frequent cancer among women, with an estimated 1.67 million new cancer cases diagnosed in 2012 (25\% of all cancers). ${ }^{1}$ Kosovo is located in the central Balkan peninsula and has a resident population of 1.8 million, of whom $92.9 \%$ are of Albanian ethnicity. ${ }^{2}$ In Kosovo, cancer care is mainly provided at the Institute of Oncology of the University Clinical Centre of Kosovo (UCCK). It is a national institute for cancer treatment and provides only outpatient care for cancer patients in Kosovo. According to the annual report for 2011 by the Kosovo Institute of Public Health (IPH), the most
Correspondence: Selvete Shuleta-Qehaja Kosovo Medicines Agency, Rrethi i spitalit (QKUK), Pristina, Kosovo $\mathrm{Tel}+37744120902$

Fax +38I 38512243

Email sshuleta@yahoo.com 
common diagnosis in tumors group classification was breast cancer $(11.8 \%){ }^{3}$ The diagnosis and subsequent treatment of cancer is often associated with considerable psychological and social difficulties for patients. ${ }^{4}$ Quality of life (QoL) has become a part of the evaluation criteria for cancer therapy besides the classical biomedical criteria. It is the most frequently used outcome measure in oncology research. ${ }^{5}$ In Kosovo, there is very little information available about the QoL of cancer patients.

The European Organization for Research and Treatment of Cancer Quality of Life Questionnaire (EORTC QLQ-C30) is a questionnaire to assess the QoL in cancer patients. The QLQ-C30 questionnaire has been used worldwide. ${ }^{6}$ The Albanian QLQ-C30 version has been translated by EORTC, and to our knowledge, this is the first evaluation of the questionnaire. Therefore, the purpose of the current study was to evaluate the validity and reliability of the QLQ-C30 in Albanian women with breast cancer.

\section{Patients and methods}

A random sample of 62 breast cancer women patients, who were attending the Institute of Oncology of the UCCK were included in the study. The study period was between the end of February 2014 until the middle of May 2014. The study was approved by the ethics committee from UCCK. Patients were informed about the purpose of the study questionnaire and were voluntarily included in the study and gave verbal informed consent. The personal interview with patients was conducted by the clinician. Only patients who were able to follow the questions and give answers were interviewed. Patients were interviewed only once during the study. There were no exclusions in patient selection in terms of disease stage, age, and the type of treatment at the time of the interview. Sociodemographic data of patients (age, marital status, and education status) were taken during the interview and clinical information (disease stage, metastasis, and types of treatment) was collected from patients' medical records. Obtained results were analyzed with current published literature.

\section{Questionnaire}

The EORTC QLQ-C30 (v3.0) in Albanian and the scoring manual were kindly sent to us by the EORTC Quality of Life Group, Brussels, Belgium. The questionnaire contains five functional scales, three symptom scales, a global health (GH)/QoL scale, and six single items, and measures healthrelated QoL (HRQoL) over the past week. ${ }^{6}$ This is the core cancer-specific questionnaire (QLQ-C30) developed to be used alone, or with additional questionnaire modules, which can be site- or treatment-specific. ${ }^{7}$ Item scores of the EORTC QLQ-C30 and missing data were managed according to the EORTC QLQ-C30 scoring manual. ${ }^{8}$ After the scoring procedures, all scale and single-item scores were linearly transformed to a 0-100 scale. Higher scores for five functional scales and the global QoL scale, indicate 'higher level of functioning or global QoL', while for symptom scales and single items, a higher score indicates a 'higher level of symptoms or problems'. ${ }^{9}$

According to published studies, ${ }^{10-12}$ a problematic group was defined if $\mathrm{GH} / \mathrm{QoL}$ or the functional scales score were $\leq 33$ and symptom scale score was $\geq 66$ on the EORTC QLQ-C30.

The EORTC QLQ-C30 was developed to be selfadministered; however, interviewer administration is also recommended. ${ }^{13}$ In our study, most of the patients had no basic education or had only primary school education, making self-administration of the questionnaire difficult. Hahn at al ${ }^{14}$ showed that the mode of administering questionnaires, whether via interview or self-administration, does not interfere with the scores reported by patients.

\section{Statistical analysis}

Categorical and continuous variables were expressed with frequencies and percentages, and means and standard deviations, respectively. Reliability (internal consistency) of the questionnaire was tested by Cronbach's alpha coefficient and the acceptable value to be met was $\geq 0.70 .{ }^{15}$ Multitrait scaling analysis was used for item convergent and discriminant validity. ${ }^{16}$ Convergent validity was predicted if the correlation value of an item and its own scale was $\geq 0.40$ and discriminant validity if the correlation of an item with its own scale was higher than with other scales. ${ }^{17}$ Construct validity was evaluated under the hypothesis that the QLQ-C30 subscales were correlated with each other (acceptable correlation coefficients were $\geq 0.40$ ) and by known groups comparisons analyzing the correlation between subgroups of patients differing in disease stage and education level. The underlying hypothesis was that patients with stage III-IV cancer would report higher symptom scores than patients in earlier disease stages and patients with high school/university education would report higher functional scores and better GH/QoL than other patient subgroups. The Kruskal-Wallis test was used for between subgroup comparison analysis.

All data analyses were performed using SPSS (v20) software and $P<0.05$ was considered to be statistically significant. 


\section{Results}

\section{Sociodemographic and clinical characteristics}

Sixty-two women with breast cancer were interviewed. The patients' mean age was 50.0 years (standard deviation [SD]: 10.9), with a range of 32-80 years. Most of the patients were married $(91.9 \%)$ and had completed primary or secondary education (71\%), while $16.1 \%$ had completed high school/ university. Most of the patients had undergone chemotherapy $(96.8 \%)$ and $82.3 \%$ of the patients had undergone surgical treatment (mastectomy). The disease stage of the patients were as follows: $11.3 \%$ stage $0-\mathrm{I}, 30.6 \%$ stage II, $58.1 \%$ stage III-IV, while $29 \%$ had distant metastasis. Sociodemographic and clinical characteristics of the patients are presented in Table 1.

\section{Reliability of the Albanian version of the EORTC QLQ-C30}

Mean scores and standard deviations of each subscale/item, and Cronbach's alpha coefficients for the multi-item scales of the EORTC QLQ-C30 are shown in Table 2.

Table I Sociodemographic and clinical characteristics of the study sample $(\mathrm{n}=62)$

\begin{tabular}{|c|c|c|}
\hline Characteristics & Number of patients & $\%$ \\
\hline \multicolumn{3}{|l|}{ Age (years) } \\
\hline $20-39$ & II & 17.7 \\
\hline $40-59$ & 38 & 61.3 \\
\hline $60-80$ & 13 & 21 \\
\hline \multicolumn{3}{|l|}{ Education level } \\
\hline No school & 8 & 12.9 \\
\hline Primary & 31 & 50 \\
\hline Secondary & 13 & 21 \\
\hline High school/university & 10 & 16.1 \\
\hline \multicolumn{3}{|l|}{ Marital status } \\
\hline Single & 5 & 8.1 \\
\hline Married & 57 & 91.9 \\
\hline \multicolumn{3}{|l|}{ Chemotherapy } \\
\hline No & 2 & 3.2 \\
\hline Yes & 60 & 96.8 \\
\hline \multicolumn{3}{|l|}{ Surgery } \\
\hline No & 6 & 9.7 \\
\hline Mastectomy & 51 & 82.3 \\
\hline Lumpectomy & I & 1.6 \\
\hline Quadrantectomy & 4 & 6.5 \\
\hline \multicolumn{3}{|l|}{ Radiotherapy } \\
\hline Yes & 49 & 79 \\
\hline No & 13 & 21 \\
\hline \multicolumn{3}{|l|}{ Disease stage } \\
\hline $0-1$ & 7 & 11.3 \\
\hline II & 19 & 30.6 \\
\hline III-IV & 36 & 58.1 \\
\hline \multicolumn{3}{|l|}{ Distant metastasis } \\
\hline No & 44 & 71 \\
\hline Yes & 18 & 29 \\
\hline
\end{tabular}

Table 2 Mean scores and internal consistency of each subscale/ item of EORTC QLQ-C30 (n=62)

\begin{tabular}{|c|c|c|}
\hline & $\begin{array}{l}\text { Mean score } \\
\text { (SD) }\end{array}$ & $\begin{array}{l}\text { Cronbach's alpha } \\
\text { coefficients }^{\mathrm{a}}\end{array}$ \\
\hline \multicolumn{3}{|l|}{ Functional scale ${ }^{b}$} \\
\hline Physical $(I-5)^{c}$ & $82.58(16.34)$ & 0.81 \\
\hline Role $(6,7)^{c}$ & $65.6(20.88)$ & 0.81 \\
\hline Emotional $(2 I-24)^{c}$ & $57.13(21.6)$ & 0.86 \\
\hline Cognitive $(20,25)^{c}$ & $65.05(27.6 I)$ & 0.54 \\
\hline Social $(26,27)^{c}$ & $54.53(19.67)$ & 0.8 \\
\hline $\begin{array}{l}\text { Global health quality } \\
\text { of life }(29,30)^{c}\end{array}$ & $78.9(17.63)$ & 0.96 \\
\hline \multicolumn{3}{|c|}{ Symptom scale and/or items ${ }^{d}$} \\
\hline Fatigue $(10,12,18)^{c}$ & $19.61(24.6)$ & 0.91 \\
\hline $\begin{array}{l}\text { Nausea and vomiting } \\
(14,15)^{c}\end{array}$ & $6.99(19.21)$ & 0.77 \\
\hline Pain $(9,19)^{c}$ & $20.16(23.2)$ & 0.83 \\
\hline Dyspnea $(8)^{c}$ & $19.35(28.01)$ & \\
\hline Insomnia $(\mathrm{II})^{c}$ & $40.33(40.1)$ & \\
\hline Appetite loss (13) c & $21.5(34.2)$ & \\
\hline Constipation $(16)^{c}$ & $1.61(12.7)$ & \\
\hline Diarrhea $(17)^{c}$ & $6.45(19.87)$ & \\
\hline Financial difficulties $(28)^{c}$ & $92.47(22.92)$ & \\
\hline
\end{tabular}

Notes: aAlpha $\geq 0.70$ indicates acceptable scale reliability; bscores range from 0 to 100 - higher score indicates better functioning or GH/QoL; 'numbers in brackets correspond to the item numbers in the questionnaire; 'scores range from 0 to $100-$ higher score indicates a higher rate of symptoms or problems.

Abbreviations: EORTC QLQ-C30, European Organization for Research and Treatment of Cancer Quality of Life Core Questionnaire; GH/QoL, global health quality of life; SD, standard deviation.

The mean scores for the GH/QoL, physical, role, emotional, cognitive, and social functioning subscales were above 33 , suggesting that there were no problems regarding their functioning. The mean scores of the symptom scales were less than 66 for almost all of the symptom scales and/or items suggesting lack of severe symptomatology among patients, with the exception of financial difficulties, with a mean score of 92.47, indicating financial problems for women with breast cancer.

Eight subscales achieved the acceptable standard of reliability ( $\geq 0.70$ ), the only exception was the cognitive scale which had a Cronbach's alpha coefficient of 0.54 . The highest score of internal consistency was 0.96 for GH/QoL.

\section{Validity of the Albanian version of EORTC QLQ-C30 Multitrait scaling analysis: convergent and discriminant validity}

The convergent validity testing showed that all correlation coefficients between an item and its own subscale were $\geq 0.40$ with the exception of item 5 (self-care; $\rho=-0.22$ ). Spearman's correlation coefficients between each item and its 
Table 3 Spearman's correlation coefficients between the items and the subscales of the EORTC QLQ-C30

\begin{tabular}{|c|c|c|c|c|c|c|c|c|c|c|}
\hline \multicolumn{2}{|c|}{ Item correlations } & \multicolumn{9}{|c|}{ Subscales } \\
\hline Item no ${ }^{a}$ & Short description ${ }^{b}$ & PF & RF & EF & CF & SF & GH/QoL & FA & NV & PA \\
\hline I & Strenuous activities & $-0.79^{c}$ & -0.37 & -0.3 & -0.34 & -0.17 & -0.65 & 0.63 & 0.21 & 0.54 \\
\hline 2 & Long walk & -0.77 & -0.34 & -0.32 & -0.26 & -0.41 & -0.45 & 0.5 & 0.34 & 0.44 \\
\hline 3 & Short walk & -0.60 & -0.11 & -0.34 & -0.23 & -0.28 & -0.58 & 0.51 & 0.29 & 0.44 \\
\hline 4 & Stay in bed/chair & -0.70 & -0.08 & -0.20 & -0.30 & -0.27 & -0.55 & 0.68 & 0.44 & 0.56 \\
\hline 5 & Self-care & -0.22 & -0.23 & -0.21 & -0.20 & -0.23 & -0.23 & 0.22 & 0.33 & 0.23 \\
\hline 6 & Limited in work & -0.30 & -0.82 & -0.21 & -0.13 & -0.42 & -0.23 & 0.25 & 0.06 & 0.17 \\
\hline 7 & Hobbies/limited leisure activities & -0.33 & -0.96 & -0.30 & -0.19 & -0.31 & -0.25 & 0.24 & 0.05 & 0.20 \\
\hline 21 & Tense & -0.22 & -0.18 & -0.75 & -0.20 & -0.15 & -0.12 & 0.18 & 0.19 & 0.17 \\
\hline 22 & Worried & -0.26 & -0.19 & -0.85 & -0.39 & -0.43 & -0.26 & 0.11 & 0.29 & 0.28 \\
\hline 23 & Irritated & -0.30 & -0.16 & -0.84 & -0.16 & -0.18 & -0.22 & 0.15 & 0.26 & 0.22 \\
\hline 24 & Depressed & -0.40 & -0.31 & -0.74 & -0.37 & -0.36 & -0.38 & 0.35 & 0.24 & 0.31 \\
\hline 20 & Concentration & -0.18 & -0.06 & -0.25 & -0.76 & -0.34 & $-0.4 I$ & 0.29 & 0.20 & 0.39 \\
\hline 25 & Memory difficulties & -0.35 & -0.11 & -0.32 & -0.89 & -0.40 & $-0.4 I$ & 0.32 & 0.20 & 0.18 \\
\hline 26 & Family life & -0.33 & $-0.4 I$ & -0.35 & -0.39 & -0.85 & -0.25 & 0.23 & 0.26 & 0.19 \\
\hline 27 & Social life & $-0.4 \mathrm{I}$ & -0.36 & -0.39 & -0.44 & -0.84 & -0.42 & 0.42 & 0.52 & 0.29 \\
\hline 29 & Physical condition & 0.71 & 0.18 & 0.34 & 0.48 & 0.36 & 0.98 & -0.73 & -0.45 & -0.69 \\
\hline 30 & General QoL & 0.62 & 0.21 & 0.34 & $0.5 I$ & 0.40 & 0.98 & -0.69 & -0.40 & -0.60 \\
\hline 10 & Need to rest & -0.57 & -0.26 & -0.22 & -0.27 & -0.37 & -0.60 & 0.89 & 0.48 & 0.60 \\
\hline 12 & Felt weak & $-0.6 \mathrm{I}$ & -0.20 & -0.26 & -0.35 & $-0.4 \mathrm{I}$ & -0.68 & 0.83 & 0.54 & 0.60 \\
\hline 18 & Felt tired & $-0.7 \mid$ & -0.07 & -0.26 & -0.30 & -0.21 & -0.63 & 0.78 & 0.47 & 0.62 \\
\hline 14 & Nausea & $-0.4 I$ & -0.02 & -0.26 & -0.25 & -0.44 & -0.43 & 0.49 & 0.95 & 0.45 \\
\hline 15 & Vomiting & -0.31 & 0.02 & -0.30 & -0.14 & -0.17 & -0.33 & 0.28 & $0.7 I$ & 0.30 \\
\hline 9 & Had pain & -0.52 & -0.13 & -0.26 & -0.36 & -0.27 & -0.59 & 0.59 & 0.46 & 0.90 \\
\hline 19 & Pain interfered & -0.65 & -0.20 & -0.32 & -0.25 & -0.28 & -0.60 & 0.68 & 0.38 & 0.89 \\
\hline
\end{tabular}

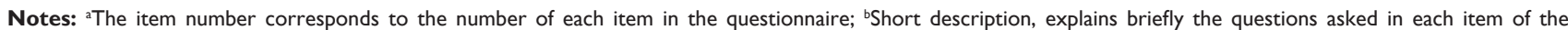
questionnaire; 'Spearman's correlation coefficients between the subscales and items within the same subscale (in bold).

Abbreviations: CF, cognitive functioning; EF, emotional functioning; EORTC QLQ-C30, European Organization for Research and Treatment of Cancer Quality of Life Core Questionnaire; FA, fatigue; GH/QoL, global health quality of life; NV, nausea and vomiting; RF, role functioning; PA, pain; PF, physical functioning; QoL, quality of life; SF, social functioning.

own subscale are presented in Table 3 . The correlation coefficients ranged from -0.22 to 0.98 . Item 7 (hobbies/limited leisure activities) had the strongest negative correlation with its corresponding role functioning subscale, as well as item 25 (memory difficulties) with its corresponding cognitive functioning subscale. Items 29 (physical condition) and 30 (general QoL) had the strongest positive correlation with their corresponding GH/QoL as well as item 14 (nausea) with its corresponding nausea and vomiting subscale. The results for item discriminant validity were satisfactory, with the exception of item 5 (self-care), which showed higher correlation with other subscales (role functioning, social functioning, $\mathrm{GH} / \mathrm{QoL}$, vomiting and pain) than with its corresponding physical functioning subscale.

\section{Construct validity}

Generally, the QLQ-C30 subscales showed moderateto-strong correlation with each other. The exception was a strong relationship between fatigue and $\mathrm{GH} / \mathrm{QoL}(\rho=0.73)$, fatigue with physical functioning $(\rho=0.72)$, and pain with fatigue ( $\rho=0.70$ ). Spearman's correlation coefficients among nine subscales are presented in Table 4.

Findings of known group comparisons according to the disease stage generally showed that patients with advanced stages of breast cancer (stages III-IV) had higher symptomatic scores than those in early stages. However, none of these differences was statistically significant in the present study (Table 5).

In terms of education level, patients with high school/ university education reported higher cognitive functioning compared to the other subgroups ( $P=0.03$ ); other functional scales differences were not statistically significant. Interestingly, patients with secondary school education showed better GH/QoL than patients with high school/university education $(P=0.009$; Table 6$)$.

\section{Discussion}

This initial study was designed to evaluate the reliability and validity of the EORTC QLQ-C30 (v3.0) in Albanian and is an attempt to provide initial information regarding its validity 
Table 4 Spearman's correlation coefficients of subscales in the Albanian version of the EORTC QLQ-C30

\begin{tabular}{|c|c|c|c|c|c|c|c|c|}
\hline Scales & PF & RF & EF & CF & SF & GH/QoL & FA & NV \\
\hline \multicolumn{9}{|l|}{ PF } \\
\hline RF & $0.34 * *$ & & & & & & & \\
\hline $\mathrm{EF}$ & $0.38 * *$ & $0.28^{*}$ & & & & & & \\
\hline $\mathrm{CF}$ & $0.34 * *$ & 0.13 & $0.36 * *$ & & & & & \\
\hline SF & $0.42 * *$ & $0.37 * *$ & $0.38 * *$ & $0.44 * *$ & & & & \\
\hline GH/QoL & $0.68 * *$ & $0.19 * *$ & $0.35^{* *}$ & $0.50^{* *}$ & $0.38 * *$ & & & \\
\hline FA & $-0.72 * *$ & -0.22 & -0.23 & $-0.37 * *$ & $-0.38 * *$ & $-0.73^{* *}$ & & \\
\hline NV & $-0.40 * *$ & -0.02 & $-0.25^{*}$ & -0.25 & $-0.45^{* *}$ & $-0.43 * *$ & $0.50 * *$ & \\
\hline PA & $-0.64 * *$ & -0.17 & $-0.32 *$ & $-0.34 * *$ & $-0.29 *$ & $-0.66 * *$ & $0.70 * *$ & $0.46^{* *}$ \\
\hline
\end{tabular}

Notes: *Correlation is significant at the 0.05 level (two-tailed); **correlation is significant at the 0.01 level (two-tailed); negative correlations are due to scoring procedures.

Abbreviations: CF, cognitive functioning; EF, emotional functioning; EORTC QLQ-C30, European Organization for Research and Treatment of Cancer Quality of Life Core Questionnaire; FA, fatigue; GH/QoL, global health quality of life; NV, nausea and vomiting; RF, role functioning; PA, pain; PF, physical functioning; SF, social functioning.

and reliability in women with breast cancer in Kosovo. As an initial study, a sample size of 62 was selected since it can identify correlations of $\geq 0.35$ with a power of $80 \%$ at a $P$-value of $0.05 .^{18,19}$

The translation of the EORTC QLQ-C30 into Albanian was carried out by the EORTC Group. Our results indicate that internal consistency is acceptable, with the exception of the cognitive functioning scale (alpha $=0.54$ ); this has been reported in other studies as well. ${ }^{19-22}$ The predicted convergent validity was supported, regarding hypothesized correlation coefficients between an item and its own subscales, with the exception of item 5 (self-care). To an extent, similar findings regarding item 5 were reported in published studies. ${ }^{23,24}$ The results of discriminant validity were satisfactory, with the exception of item 5 (self-care), which showed a higher correlation with role and social functioning, GH/QoL subscale, nausea/vomiting, and pain than with its corresponding physical functioning subscale. Total item-discriminant validity success was $89.1 \%$.

Interscale construct validity was generally supported by confirmation of predicted correlations between subscales that are theoretically related, although strong correlations were found between fatigue with physical functioning, fatigue with pain, and fatigue with GH/QoL, which are considered unacceptable and may question the diversity of the notions being measured. The only possible explanation for these high correlations is that patients correlated fatigue (felt weak, felt tired, needed to rest) with their ability to accomplish a strenuous activity, take a long walk, necessity to stay in bed/chair, presence of pain, or their physical condition. Nevertheless, further studies are recommended.

Results of known group comparison analysis showed that there were no statistically significant differences between patients differing in disease stage. Our results were compatible with studies that reported that the stage of disease is not associated with QoL. ${ }^{25,26}$ In terms of education level, our findings showed that patients with high school/university education reported higher cognitive functioning compared to other subgroups; other functional scale differences were not statistically significant. Interestingly, patients with secondary school education showed better GH/QoL than patients with high school/university education. Many studies found that

Table 5 Summary of the EORTC QLQ-C30 subscales by disease stage

\begin{tabular}{|c|c|c|c|c|}
\hline \multirow[t]{2}{*}{ Disease stage } & \multirow{2}{*}{$\begin{array}{l}0-1 \\
n=7\end{array}$} & \multirow{2}{*}{$\frac{\text { II }}{n=19}$} & \multirow{2}{*}{$\begin{array}{l}\text { III-IV } \\
n=36\end{array}$} & \multirow[t]{3}{*}{$P$-value* } \\
\hline & & & & \\
\hline Symptom scale & $\overline{\text { Mean (SD) }}$ & $\overline{\text { Mean (SD) }}$ & Mean (SD) & \\
\hline Fatigue & $10.9(13.0)$ & $19.6(23.7)$ & $21.3(26.8)$ & 0.68 \\
\hline Nausea and vomiting & $0.0(0.0)$ & $5.3(I 3.7)$ & $9.3(23.0)$ & 0.44 \\
\hline Pain & $11.9(15.9)$ & $21.0(24.1)$ & $21.3(24.1)$ & 0.63 \\
\hline Dyspnea & $14.3(17.8)$ & I2.8 (27.7) & $24.1(29.4)$ & 0.16 \\
\hline Insomnia & $42.9(46.0)$ & $42.1(41.3)$ & $38.9(39.4)$ & 0.94 \\
\hline Appetite loss & $4.8(12.6)$ & $19.3(33.9)$ & $25.9(36.6)$ & 0.26 \\
\hline Constipation & $0.0(0.0)$ & $0.0(0.0)$ & $2.8(16.7)$ & 0.70 \\
\hline Diarrhea & $4.8(12.6)$ & $7.0(23.8)$ & $6.5(19.2)$ & 0.95 \\
\hline Financial difficulties & $85.7(26.2)$ & $96.5(15.3)$ & 92.5 (22.9) & 0.29 \\
\hline
\end{tabular}

Note: $* P<0.05$ is considered statistically significant.

Abbreviations: EORTC QLQ-C30, European Organization for Research and Treatment of Cancer Quality of Life Core Questionnaire; SD, standard deviation. 
Table 6 Summary of the EORTC QLQ-C30 subscales by education level

\begin{tabular}{|c|c|c|c|c|c|}
\hline \multirow[t]{2}{*}{ Education level } & No school & Primary & Secondary & High school/university & $P$-value* \\
\hline & $\mathbf{n}=\mathbf{8}$ & $n=31$ & $n=13$ & $n=10$ & \\
\hline Functional scale & Mean (SD) & Mean (SD) & Mean (SD) & Mean (SD) & \\
\hline Physical functioning & $78.3(6.9)$ & $82.6(14.1)$ & 86.7 (12.5) & 80.7 (29.4) & 0.17 \\
\hline Role functioning & $66.7(25.2)$ & $65.6(15.5)$ & $71.8(21.9)$ & $56.7(29.6)$ & 0.42 \\
\hline Cognitive functioning & $47.9(18.8)$ & $61.3(28.7)$ & 71.8 (2I.9) & $81.7(28.8)$ & 0.03 \\
\hline Emotional functioning & $60.4(23.9)$ & $55.4(15.6)$ & $56.4(29.5)$ & $60.8(26.7)$ & 0.27 \\
\hline Social functioning & $56.3(15.3)$ & $62.9(14.8)$ & $68.0(25.9)$ & $71.7(26.1)$ & 0.31 \\
\hline GH/QoL & $65.6(10.4)$ & 77.7 (15.9) & $86.6(13.4)$ & $83.3(26.0)$ & 0.009 \\
\hline
\end{tabular}

Note: $* P<0.05$ is considered statistically significant.

Abbreviations: EORTC QLQ-C30, European Organization for Research and Treatment of Cancer Quality of Life Core Questionnaire; GH/QoL, global health quality of life; SD, standard deviation.

education level affects QoL of cancer patients. ${ }^{27,28}$ Pinar et $\mathrm{al}^{29}$ found that university-educated patients had the highest QoL scores. Another research reported that women with college education showed better overall QoL. ${ }^{30} \mathrm{On}$ the other hand, there are studies that reported no significant differences between the educational level of patients and QoL ${ }^{31-33}$ and to some extent, our results were similar with their findings.

However, the results of the present study should be considered with caution since it is a preliminary study with a small number of patients; further studies are recommended to assess the findings.

\section{Conclusion}

In this initial study, the EORTC QLQ-C30 (v3.0) in Albanian was found to be reliable and valid for women with breast cancer.

Although the sample size was small and the study only included women with breast cancer, it is still important due to its preliminary findings on the validity and reliability of the EORTC QLQ-C30 in Albanian. It provides the basis for future studies of the EORTC QLQ-C30 in Kosovo and other countries in Albanian-speaking cancer patients. Studies with larger numbers of patients, including male patients as well as other groups of cancer patients and test-retest reliability are recommended to assess the results of this initial study.

\section{Author contributions}

Selvete Shuleta-Qehaja and Zoran Sterjev designed the study and all authors interpreted the data and revised the manuscript. Selvete Shuleta-Qehaja and Zoran Sterjev managed the statistical analysis. All authors read and approved the final manuscript.

\section{Disclosure}

The authors report no conflicts of interest in this work.

\section{References}

1. Breast Cancer Estimated Incidence, Mortality and Prevalence Worldwide in 2012 [webpage on the Internet]. Geneva, Switzerland: World Health Organization; 2012. Available from: http://globocan.iarc.fr/ Pages/fact_sheets_cancer.aspx. Accessed June 10, 2014.

2. Kosovo Agency of Statistics. Available from: ask.rks-gov.net/ rekos2011/repository/docs/Final\%20Results_ENG.pdf. Accessed June 16, 2014.

3. Morbidity analysis of Kosovo population in 2011 [webpage on the Internet]. Prishtina, Kosovo: National Institute of Public Health of Kosova; 2011. Available from: http://www.niph-kosova.org/. Accessed June 16, 2014.

4. Cankurtan ES, Ozalp E, Soygur H, Akbiyik DI, Bottomley A. Understanding the reliability and validity of EORTC QLQ-C30 in Turkish cancer patients. Eur J Cancer Care (Engl). 2008;17(1): 98-104.

5. Lee SJ, Earle CC, Weeks JC. Outcomes research in oncology: history, conceptual framework, and trends in the literature. J Natl Cancer Inst. 2000;92(3):195-204.

6. Aaronson NK, Ahmedzai S, Bergman B, et al. The European Organization for Research and Treatment of Cancer QLQ-C30: a quality-of-life instrument for use in international clinical trials in oncology. $J$ Natl Cancer Inst. 1993;85(5):365-376.

7. EORTC QLQ-C30 [homepage on the Internet]. Brussels, Belgium: EORTC Quality of Life Department. Available from: http://groups. eortc.be/qol/eortc-qlq-c30. Accessed June 26, 2014.

8. Fayers PM, Aaronson NK, Bjordal K, Groenvold M, Curran D, Bottomley A; EORTC Quality of Life Group. The EORTC QLQ-C3O Scoring Manual. 3rd ed. Brussels, Belgium: European Organisation for Research and Treatment of Cancer; 2001.

9. McLachlan SA, Devins GM, Goodwin PJ. Validation of the European Organization for Research and Treatment of Cancer Quality of Life Questionnaire (QLQ-C30) as a measure of psychosocial function in breast cancer patients. Eur J Cancer. 1998;34(4): 510-517.

10. Ahn SH, Park BW, Noh DY, et al. Health-related quality of life in disease-free survivors of breast cancer with the general population. Ann Oncol. 2007;18(1):173-182.

11. Waldman A, Prikuleit R, Raspe H, Katalinic A. The OVIS study: health related quality of life measured by the EORTC QLQ-C30 and -BR23 in German female patients with breast cancer from Schleswig-Holstein. Qual Life Res. 2007;16(5):767-776.

12. Alawadhi SA, Ohaeri JU. Validity and reliability of the European Organization for Research and Treatment in Cancer Quality of Life Questionnaire (EORTC QLQ): experience from Kuwait using a sample of women with breast cancer. Ann Saudi Med. 2010;30(5): 390-396.

13. Paiva CE, Carneseca EC, Barroso EM, et al. Further evaluation of the EORTC QLQ-C30 psychometric properties in a large Brazilian cancer patient cohort as a function of their educational status. Support Care Cancer. 2014;22(8):2151-2160. 
14. Hahn EA, Rao D, Cella D, Choi SW. Comparability of interview- and self-administration of the Functional Assessment of Cancer TherapyGeneral (FACT-G) in English- and Spanish-speaking ambulatory cancer patients. Med Care. 2008;46(4):423-431.

15. Nunnally JC, Bernstein IH. Psychometric theory. 3rd ed. New York, NY: McGraw-Hill; 1994.

16. Hays RD, Hayashi T. Beyond internal consistency reliability: rationale and user's guide for multitrait analysis program on the microcomputer. Behav Res Meth Instrum Comput. 1990;22(2):167-175.

17. Silpakit Ch, Sirilerttrakul S, Jirajarus M, Sirisinha Th, Sirachainan E, Ratanatharathorn V. The European Organization for Research and Treatment of Cancer Quality of Life Questionnaire (EORTC QLQC30): validation study of the Thai version. Qual Life Res. 2006;15(1): $167-172$.

18. Gatsonis C, Sampson AR. Multiple correlation: exact power and sample size calculations. Psychol Bull. 1989;106(3):516-524.

19. Luo N, Fones CS, Lim SE, Xie F, Thumboo J, Li SC. The European Organization for Research and Treatment of Cancer Quality of Life Questionnaire (EORTC QLQ-C30): validation of English version in Singapore. Qual Life Res. 2005;14(4):1181-1186.

20. Kontodimopoulos N, Ntinoulis K, Niakas D. Validity of the Greek EORTC QLQ-C30 and QLQ-BR23 for measuring health-related quality of life in breast cancer patients. Eur J Cancer Care (Engl). 2011;20(3): 354-361.

21. Awad MA, Denic S, El Taji H. Validation of the European Organization for Research and Treatment of Cancer Quality of Life Questionnaires for Arabic-speaking Populations. Ann N Y Acad Sci. 2008;1138:146-154.

22. Wan $\mathrm{C}$, Tang $\mathrm{X}, \mathrm{Tu} \mathrm{XM}$, et al. Psychometric properties of the simplified Chinese version of the EORTC QLQ-BR53 for measuring quality of life for breast cancer patients. Breast Cancer Res Treat. 2007;105(2):187-193.

23. Hoopman R, Muller MJ, Terwee CB, Aaronson NK. Translation and validation of the EORTC QLQ-C30 for use among Turkish and Moroccan ethnic minority cancer patients in the Netherlands. Eur J Cancer. 2006;42(12):1839-1847.
24. Huijer HA, Sagherian K, Tamim H. Validation of the Arabic version of the EORTC QLQ-C30 quality of life questionnaire among cancer patients in Lebanon. Qual Life Res. 2013;22(6):1473-1481.

25. Parker PA, Baile WF, de Moore Cd, Cohen L. Psychosocial and demographic predictors of quality of life in a large sample of cancer patients. Psychooncology. 2003;12(2):181-193.

26. Janz NK, Mujahid M, Lantz PM, et al. Population-based study of the relationship of treatment and sociodemographics on quality of life for early stage breast cancer. Qual Life Res. 2005;14(6):1467-1479.

27. Akin S, Can G, Durna Z, Aydiner A. The quality of life and self-efficacy of Turkish breast cancer patients undergoing chemotherapy. Eur J Cancer Nursing. 2008;12(5):449-456.

28. Cui Y, Shu XO, Gao Y, et al. The long-term impact of medical and sociodemographic factors on the quality of life of breast cancer survivors among Chinese women. Breast Cancer Res Treat. 2004;87(2):135-147.

29. Pinar R, Salepci T, Afsar F. Assessment of quality of life in Turkish patients with cancer. Turkish J Cancer. 2003;33(2):96-101.

30. Uzun O, Aslan FE, Selimen D, Koç M. Quality of life in women with breast cancer in Turkey. J Nurs Scholarsh. 2004;36(3):207-213.

31. Guner P, Isikhan V, Kömürcü S, et al. Quality of life and sociodemographic characteristics of patients with cancer in Turkey. Oncol Nurs Forum. 2006;33(6):1171-1176.

32. Ogce F, Ozkan S, Baltalarli B. Psychosocial stressors, social support and socio-demographic variables as determinants of quality of life of Turkish breast cancer patients. Asian Pac J Cancer Prev. 2007;8(1): 77-82.

33. Kwan ML, Ergas IJ, Somkin CP, et al. Quality of life among women recently diagnosed with invasive breast cancer: the Pathways Study. Breast Cancer Res Treat. 2010;123(2):507-524.
Patient Preference and Adherence

\section{Publish your work in this journal}

Patient Preference and Adherence is an international, peer-reviewed, open access journal that focuses on the growing importance of patient preference and adherence throughout the therapeutic continuum. Patient satisfaction, acceptability, quality of life, compliance, persistence and their role in developing new therapeutic modalities and compounds to optimize

\section{Dovepress}

clinical outcomes for existing disease states are major areas of interest for the journal. This journal has been accepted for indexing on PubMed Central. The manuscript management system is completely online and includes a very quick and fair peer-review system, which is all easy to use. Visit http://www. dovepress.com/testimonials.php to read real quotes from published authors. 